\title{
Did Italy Need More Labour Flexibility?
}

\section{The Consequences of the Jobs Act}

The dramatic impact of the 2008 crisis on the Italian economy led to policy responses including structural reforms and labour market liberalisation to reverse the worrisome output and employment trends. A key action by the Italian government, the evocatively named Jobs Act of 2014, has deeply changed Italian industrial relations. The Jobs Act has introduced a new contract type that substantially limits workers' rights to reinstatement in case of firms invalidly firing them. This article frames the Jobs Act within the overall liberalisation process begun in Italy in the 1990s, providing an initial evaluation of its impacts. Using detailed data sources, we show that the expected boost in employment cannot be detected, the share of temporary contracts over open-ended ones has increased and the number of part-time contracts has risen. This evidence suggests that the Jobs Act is failing to achieve its main goals.

The 2008 financial crisis dramatically impacted the Italian economy. The main effects have been experienced in terms of reductions in GDP and the destruction of jobs and productive capacity. The Italian unemployment rate nearly doubled from $6.7 \%$ in 2006 to $12.7 \%$ in 2014; over the same period, Italian GDP dropped by $7.1 \%$ and the productive capacity by $25 \%$. $^{1}$ As a result, a set of policy interventions were put in place to reverse the negative trend affecting the economy.

In late 2014, the Italian government attempted to staunch the increasing unemployment through a reform of the

\footnotetext{
This paper is produced as part of the ISIGrowth project on Innovation-fuelled, Sustainable, Inclusive Growth that has received funding from the European Union's Horizon 2020 research and innovation programme under grant agreement No. 649186 - ISIGrowth. The authors wish to thank Giovanni Dosi, Mario Pianta and Maria Enrica Virgillito for their comments and suggestions. All the usual disclaimers apply.

1 Eurostat and OECD data.
}

Marta Fana, Institut d'Etudes Politiques de Paris, France.

Dario Guarascio, Sant'Anna School of Advanced Studies, Pisa, Italy.

Valeria Cirillo, Sant'Anna School of Advanced Studies, Pisa, Italy. labour market. It introduced Law 183/2014, evocatively named the "Jobs Act", which established a deep change in industrial relations via a substantial reduction of workers' protections. This completed a deregulation process that had begun in the mid-1990s. Thus, in line with the other Southern European countries, Italy relied on labour market liberalisation to increase employment, foster productivity and restart growth. The Jobs Act has been the main pillar of this agenda. In addition, the Law has the objective of countering labour market dualism and encouraging permanent employment. ${ }^{2}$

The Jobs Act has several key features. First, a new contract type has been introduced for new hires, "contratto a tutele crescenti", which eliminates any obligation for workers' reinstatement in case firms invalidly fire them. Second, the legal constraints for firms intending to monitor workers through electronic devices of various kinds have been weakened. Third, the use of temporary contracts has been facilitated by the elimination of previous restrictions on their adoption; before implementation of the Jobs Act, no more than $20 \%$ of a firms' contracts could be temporary. Moreover, just before the introduction of the new contract type, a substantial monetary incentive was provided to firms hiring under a permanent

2 An analysis of the emergency interventions previous to the Jobs Act can be found in V. Monastiriotis, N. Hardiman, A. Regan, C. Goretti, L. Landi, J.I. Conde-Ruiz, C. Marín, R. Cabral: Austerity Measures in Crisis Countries - Results and Impact on Mid-term Development, in: Intereconomics, Vol. 48, No. 1, 2013, pp. 4-32. 
contract or transforming other contracts into permanent ones.

The Italian case turns out to be revealing, especially when framed within the European debate regarding the appropriateness of austerity policies and labour market liberalisation as tools to recover growth and employment after the crisis. Italy shares with some other Southern European countries a series of dubious economic achievements: the highest rate of long-term unemployment, the highest youth unemployment rate, the lowest participation rate of women and older workers, and, lastly, one of the lowest employment rates in Europe. At the same time, a huge amount of flexibility has been introduced into the Italian labour market, with the Jobs Act constituting the final and most radical step in this direction. ${ }^{3}$

Since the 1990s, the mainstream approach to tackling the Italian economy's weaknesses has been based on removing market "rigidities", which were considered responsible for hampering (labour) market clearing, preventing efficient factor allocation and, as a consequence, avoiding social welfare maximisation. Examples of such rigidities are strong trade unions, generous social benefits, high minimum wages, powerful insiders and firing restrictions. In particular, employment protection has been increasingly seen as an obstacle to job creation due to the high costs of dismissals. Accordingly, many forms of employment protection have been identified as the major cause of longer spells of unemployment. ${ }^{4}$ However, a large strand of literature challenges the thesis supporting the need for structural reforms - directed at removing such rigidities - and labour market liberalisation. Howell et al. highlighted the fragility of the available econometric evidence which has found a positive impact of labour market liberalisation on employment, productivity and innovation dynamics. ${ }^{5}$ On similar lines, Baker et al. and Avdagic show that many findings in the empirical literature which support liberalisation are sensitive to changes in data, model specification and econometric

3 M. Fana, D. Guarascio, V. Cirillo: Labour market reforms in Italy: evaluating the effects of the Jobs Act, LEM Working Paper Series 2015/31, 2015.

4 S. Scarpetta, T. Tressel: Boosting Productivity via Innovation and Adoption of New Technologies: Any Role for Labor Market Institutions?, World Bank Policy Research Working Paper, No. 3273, 2004; A. Ichino, R.T. Riphahn: The Effect of Employment Protection on Worker Effort: Absenteeism during and after Probation, in: Journal of the European Economic Association, Vol. 3, No. 1, 2005, pp. 120-143; T. Boeri, P. Garibaldi: Two Tier Reforms of Employment Protection: a Honeymoon Effect?, in: The Economic Journal, Vol. 117, No. 521, 2007, pp. 357-385.

5 D.R. Howell, D. Baker, A. Glyn, J. Schmitt: Are Protective Labor Market Institutions at the Root of Unemployment? A Critical Review of the Evidence, in: Capitalism and Society, Vol. 2, No. 1, 2007. techniques. ${ }^{6}$ Moreover, neither Armingeon and Baccaro nor Avdagic find a statistically significant relationship between employment protection and unemployment, while Noelke does not find any evidence regarding the link between employment protection and negative employment performance for low-skilled and young workers. ${ }^{7}$

Despite this lack of consensus in labour market studies and policy prescriptions, as well as the disappointing productivity and employment performance throughout the reform process, Italy undertook a reform path in which labour market liberalisation played a fundamental role. As argued above, the 2008 crisis provoked a substantial acceleration in this process. Pini as well as Cirillo and Guarascio have discussed the rationale for and the potential implications of this further liberalisation which has been put in place during the crisis years. ${ }^{8}$ These contributions analysed the appropriateness of such a policy strategy as a way to recover competitiveness and tackle the economy's structural problems. In particular, the authors refer to the rise of structural unemployment - especially in the southern regions - and the persistent stagnation of productivity. These two negative trends were exacerbated in the aftermath of the 2008 crisis. This evidence shows that freeing firms from the remaining constraints they have in terms of labour regulations (i.e. firing restrictions) would not help to address the Italian economy's structural diseases. On the contrary, it is claimed that further reductions in firing restrictions could deepen the state of economic depression, negatively impacting the dynamics of internal demand and reducing the incentives for firms to make investments.

A further stream of literature argues that the adoption of cost competitiveness strategies in the EU periphery - with labour market liberalisation identified as a key element of such strategies - in order to recover competitiveness after the crisis could be counterproductive and damaging. Conversely, the lack of internal demand and investments - particularly innovative ones - is identified as the

6 D. Baker, A. Glyn, D.R. Howell, J. Schmitt: Labour Market Institutions and Unemployment: Assessment of the Cross-Country Evidence, in: D. Howell (ed.): Fighting Unemployment: The Limits of Free Market Orthodoxy, Oxford 2005, Oxford University Press; S. Avdag ic: Partisanship, political constraints, and employment protection reforms in an era of austerity, in: European Political Science Review, Vol. 5, No. 3, 2013, pp. 431-455.

7 C. Noelke: The Consequences of Employment Protection Legislation for the Youth Labour Market, Mannheimer Zentrum für Europäische Sozialforschung Working Paper No. 144, 2011; S. Avdagic: Does Deregulation Work? Reassessing the Unemployment Effects of Employment Protection, in: British Journal of Industrial Relations, Vol. 53, No. 1, 2015, pp. 6-26.

8 P. Pini: Il Jobs Act tra surrealismo e mistificazione: una lettura critica, in: Economia \& Lavoro, Vol. 49, No. 2, 2015, pp. 177-215; V. Cirillo, D. Guarascio: Jobs and Competitiveness in a Polarised Europe, in: Intereconomics, Vol. 50, No. 3, 2015, pp. 156-160. 
true Achilles heel of Southern European economies. The recent labour market reforms are identified as drivers of perverse incentives - pushing firms towards cost competitiveness strategies - without any capacity for tackling the economy's structural problems. ${ }^{9}$

This work aims to analyse the impact of the Jobs Act on the Italian economy, focusing on the entire liberalisation process which has taken place in Italy from the early 1990s until the present. The dynamics of key economic variables observed along the reform process - which enable us to understand labour market structural features, the economic context in which reforms were implemented as well as the economy's response - are provided to complete the picture.

Taking advantage of detailed data sources (administrative and survey data), this article evaluates the appropriateness of Law 183/2014 in the Italian and European economic context and accounts in particular for the structural effects of the recent crisis.

\section{Reforms and stylised facts}

The Italian reform process started in the 1990s with the introduction of wage bargaining decentralisation and new flexible work contracts. However, throughout the reform period, Italy's employment and labour productivity figures lagged behind those of the major EU economies. In fact, the difference between the employment rate in the EU15 and that of Italy has been around ten percentage points (in 1996 the employment rate in the EU15 was $60.1 \%$, while in Italy it was $50.1 \%$; in 2013 , the corresponding rates were $65 \%$ and $55.5 \%$ ). Furthermore, labour productivity growth remained below the EU average throughout the period (the EU rate in 1996-2013 was 1.4\%, while the Italian rate was $0.3 \%)^{10}$

From the early 1990s onwards, the Italian labour market has been affected by a number of structural weaknesses, among which three main elements are identifiable:

- The labour market participation rate for Italian women is systemically lower than the corresponding figures for males.

9 For a discussion of technological and cost competitiveness strategies as ways to tackle the European crisis, see M. Mazzucato, M. Cimoli, G. Dosi, J.E. Stiglitz, M.A. Landesmann, M. Pianta, R. Walz, T. Page: Which Industrial Policy Does Europe Need?, in: Intereconomics, Vol. 50, No. 3, 2015, pp. 120-155.

10 Authors' elaboration on Eurostat data.
- Youth employment has remained far below the EU15 average over the entire implementation period of the labour market reforms.

- A strong geographical dualism has developed, with the North growing in terms of production, employment and productivity and the South lagging behind, particularly in terms of youth and female participation in the labour market.

The persistence of such weaknesses emerges from the data. In 1992 the rate of labour market participation among men in the South was 30 percentage points higher than that of women, while in the North the difference was ten percentage points. As of the beginning of 2015, such differences in the gender participation rates have been only marginally reduced, and the reductions have been mainly due to the effects of the 2008 crisis. ${ }^{11}$ Italian youth have experienced employment rates that are more than ten percentage points below the average European ones. Moreover, the crisis gave rise to a further deepening of this divide, with a difference of around 20 percentage points in 2015.12 These structural weaknesses have been strongly persistent in terms of dynamics and intensity throughout the period during which labour market liberalisation emerged as the main course of action to face such structural challenges, i.e. from the mid-1990s until today. Indeed, a policy programme that introduced temporary contracts, facilitated dismissals and offered incentives for decentralised wage bargaining was seen as the only way to restart productivity and employment growth. With respect to the latter, temporary contracts were identified as an effective tool to facilitate youth entry into the labour market. $^{13}$

The cornerstones of the Italian reform process deserve to be underlined. The first intervention dates back to 1983-84 with the introduction of so-called training/work contracts, i.e. temporary working arrangements through which an employer employs a young worker - with a fixed term - combining ad hoc training cycles and work in the workplace. However, it was in the early 1990s that the liberalisation process accelerated with the introduction of new laws regarding collective dismissals and the definitive abolition of the automatic indexation of wages to inflation.

11 As highlighted in Cirillo and Guarascio, the last economic crisis has mostly impacted on male-dominated industrial sectors such as construction and manufacturing. This phenomenon produced an apparent rebalancing in the male-female employment divide. See V. CirilIo, D. Guarascio, op. cit.

12 Authors' elaboration on EU-LFS data.

13 P. Barbieri, S. Scherer: Labour Market Flexibilization and its Consequences in Italy, in: European Sociological Review, Vol. 25, No. 6 2009, pp. 677-692. 
In 1993 a new collective bargaining structure was introduced: the adjustment of wages to inflation dynamics would now take place at the national level and the regulation of productivity-related pay schemes would occur at the firm/regional level. ${ }^{14}$ Nevertheless, the first relevant step in the process of labour market liberalisation took place in 1997 with the so-called Pacchetto Treu (Law 196/1997). This law provided a new contractual framework, introducing apprenticeship schemes, part-time employment and temporary contracts. Private temporary work agencies were created whose aim was to facilitate the matching between supply and demand in the labour market. In 2001 the Italian government extended the possibility and the terms for the use of temporary contracts. The 2003 Legge Biagi (Law 30/2003) largely facilitated the use of staff leasing contracts, part-time work and nonstandard forms of employment relationships.

After a period of relative calm in the reform process, the 2008 crisis and its sharp consequences revived the debate concerning the need for further reforms. The Legge Fornero (Law 92/2012) of 2012 weakened the effectiveness of the "Articolo 18" of Law 300/1970, which had been the mainstay of the Italian industrial relations set-up. This law effectively protected workers from invalid lay-offs, requiring reinstatement in a number of cases. Law 92/2012 weakened this protection but did not completely abolish it. For a considerable set of cases, in fact, both the obligation of recourse to the courts in case of disputes over a dismissal as well as the possibility of workers' reinstatement were preserved. However, a definitive change entered into effect with the passage of the Jobs Act, which abolished the protections stemming from Articolo 18 of Law 300/1970 and eliminated all the residual protections for workers enrolled from then on. A detailed description of the Jobs Act will be provided below.

Summing up, the reforms implemented over the last decade in Italy determined a large flexibilisation of the labour market, both in the use of atypical contractual arrangements and in the decentralisation of the bargaining process. Labour market reforms liberalised the use of temporary forms of employment, while the firing rules for regular contracts have been gradually weakened, culminating in the recent Jobs Act.

The Italian labour market dynamics throughout the reform process can be summarised as follows. First, the overall stock of temporary employment has increased from

14 C. Jona-Lasinio, G. Vallanti: Reforms, labour market functioning and productivity dynamics: a sectoral analysis for Italy, Ministry of Economy and Finance, Department of the Treasury Working Paper No. 10, 2013.
Figure 1

Share of temporary employment in total Italian employment by age group, 1998-2015

in \%

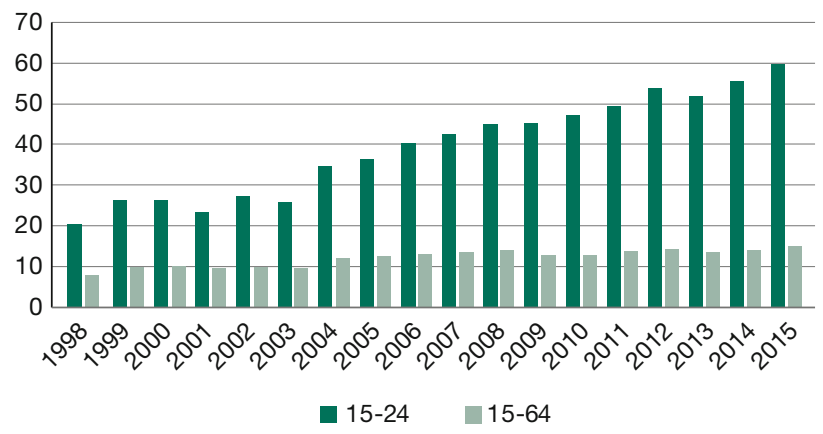

Source: Authors' elaboration on Eurostat data.

eight to $14 \%$ of total employment, as shown in Figure 1. As expected, this change has mainly affected new entrants in the labour market, proxied here by the younger cohort (15-24 years old). Remarkably, the share of young people employed with a temporary contract tripled from $20 \%$ to $60 \%$ over the period 1998-2015 (Figure 1). Generally speaking, temporary employment seems to be consistantly increasing in the Italian labour market.

Figure 2 illustrates a similar development regarding the relationship between temporary contracts and job duration. Among temporary contracts, the proportion of shortterm contracts, i.e. those lasting less than six months, has sharply increased over time. More specifically, the share of temporary employment that consists of short-term contracts with durations between one and six months has substantially increased over time, representing almost $40 \%$ of total temporary employment in 2015 . Within this category, more than $30 \%$ is due to contracts lasting a week or less. ${ }^{15}$

Second, the employment protection indicator which measures the strictness of regulation on the use of fixedterm and temporary work agency contracts decreased for temporary employment from 5.25 in 1985 to 2 in 2012, while it has remained nearly constant over time - 2.76 for regular contracts. ${ }^{16}$ From this point of view, the Italian labour market reform has contributed to the creation of a dual labour market in which fixed-term contracts - which until 2014 were characterised by a high level of protection against layoffs - coexist with temporary employment, which is in turn characterised by a low level of protection.

15 Based on authors' elaboration of Italian Ministry of Labour data. 16 See OECD/IDB Employment Protection Database. 
Figure 2

\section{Share of temporary employment by duration of} labour contract, Italy, 1998-2015

in $\%$

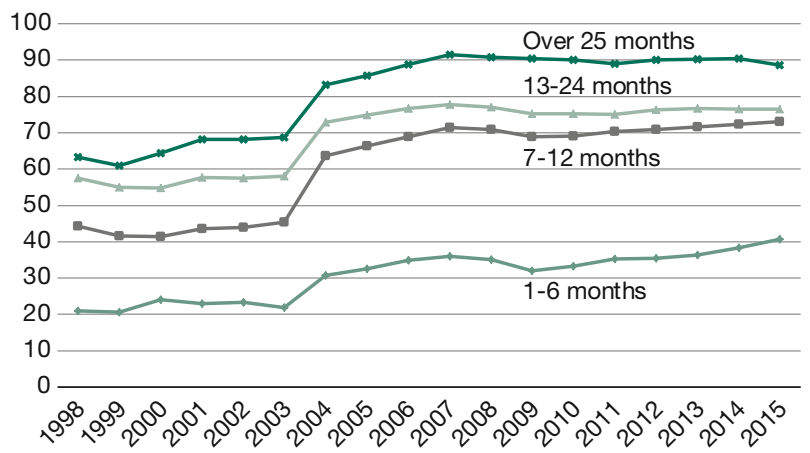

Source: Authors' elaboration on Eurostat data.

Third, the workforce skill structure in Italy has been characterised by job creation in the high and low skills groups, suggesting a trend towards polarisation and a hollowing out of the middle. Contrary to the European trend of upskilling - managers, associate professionals, technicians and clerks grew by more than one per cent per year throughout the period 2000-2013 - job creation in Italy is concentrated both in the upper and bottom parts of the skill distribution. ${ }^{17}$

As Figure 3 underlines, over the period 2000-2014, our proxy group for high-paid and high-qualified jobs - managers, technicians and associate professionals - grew by 1.5 percentage points per year. Over the same period, the clerk group grew by more than one percentage point and the manual workers group - our proxy for low-paid and low-qualified professions - grew by 0.5 percentage points. The growth of the latter category was mainly in low-tech services related to retail trade, tourism, childcare, elderly care, etc. Conversely, both in Europe and Italy, the number of craft workers decreased by almost one percentage point per year.

Fourth, the reform process does not affect the transition from unemployment to inactivity, which has remained

17 We proxy skill distribution using the International Standard Classification of Occupations (ISCO). Following Cirillo, Pianta and Nascia, we aggregate ISCO categories as follows: managers, professionals and technicians in the "managers" group; clerk workers and service workers in the "clerks" group; craft workers and skilled agricultural workers in the "craft workers" group; and manual workers and elementary occupations in the "manual" group. The aggregation into these four groups reflects educational and wage ranks of ISCO88. See V. CirilIo, M. Pianta, L. Nascia: The Shaping of Skills: Wages, Education, Innovation, in: Working Papers Series in Economics, Mathematics and Statistics, No. 2014/05, 2014.
Figure 3

Change in employment by professional group, Italy, 2000-2013

in $\%$

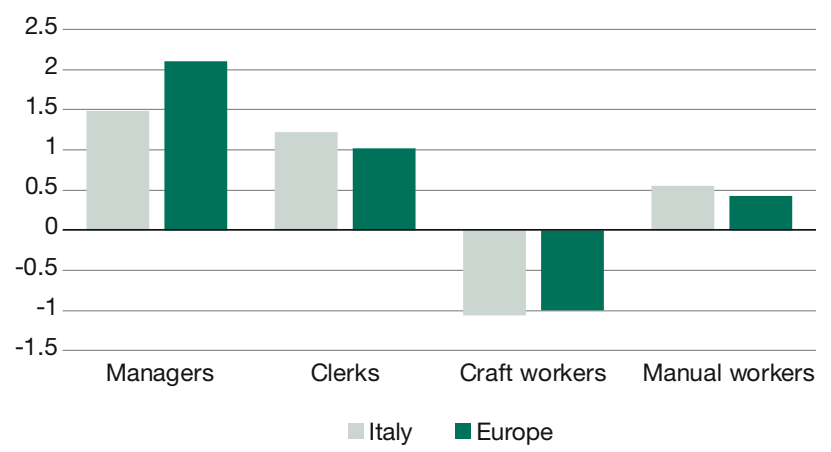

Source: Authors' elaboration on Eurostat data.

above the European average by almost 20 percentage points since 2010. Meanwhile, the transition to employment not only remained below the European mean but even decreased - from $18 \%$ in the third quarter of 2010 to $11 \%$ in the second quarter of 2015 . Overall, labour market flows suggest a deterioration of labour participation with a transition towards inactivity, probably due to long unemployment spells.

Finally, labour productivity has been declining over the entire reform period, by an average of $0.1 \%$ annually and has remained below the European average since $2000 .^{18}$ The causes of such weak performance with regard to productivity have been deeply investigated in the empirical literature, in which productivity has been found to be strongly correlated with the dynamics of R\&D expenditure, demand and investments. ${ }^{19}$

Expenditures on R\&D activities in Italy have been mostly stagnant, both in the government sector - from $0.20 \%$ in 1995 to $0.19 \%$ in 2014 - and in the business enterprise sector - from $0.50 \%$ to $0.72 \%$ - suggesting a turn towards cost-competitiveness strategies based on labour cost reductions. Overall, Italian expenditures on R\&D activities have been consistently below the EU average, which has made it more difficult, especially in the manufacturing sector, to be successful in international competition and

18 Eurostat.

19 A. Simonazzi, A. Ginzburg, G. Nocella: Economic relations between Germany and southern Europe, in: Cambridge Journal of Economics, Vol. 37, No. 3, 2013, pp. 653-675; M. Landesmann: The New North-South Divide in Europe - can the European convergence model be resuscitated?, Vienna Institute for International Economic Studies Monthly Report, No. 1, 2013, pp. 3-13. 
to be resilient during the recession that followed the 2008 crisis.

The evidence regarding the dynamics of Italian aggregate $R \& D$ expenditures over the liberalisation period helps to understand the economic context in which the labour market reforms have been put forth. As argued, the contemporaneous occurrence of R\&D weakening and sharp deregulation in industrial relations suggests a general shift towards cost-competitiveness strategies. In this light, we now turn to the main changes introduced with the Jobs Act and provide a first empirical evaluation of its impacts on the Italian economy.

\section{The Jobs Act}

The Jobs Act reformed both open-ended and atypical contracts. ${ }^{20}$ In what follows, we briefly summarise some key components of this reform.

- New standard open-ended contract - A new contract type, Contratto a tutele crescenti, was introduced for new hires that abolishes workers' reinstatement rights if firms invalidly fire them (unless the dismissal is discriminatory or is only communicated orally). This right has been substituted by minimal compensation equal to two wages per each year of work tenure. Moreover, in the case of small firms (less than 15 employees), the compensation is halved. The new law actually abolished the standard open-ended contract, removing the substantial requirement of a permanent labour relationship, since workers can now be arbitrarily fired without any economic causes.

- Electronic monitoring - The Jobs Act gives firms the authority to monitor employees through many kinds of electronic devices.

- Temporary contracts - The Jobs Act abrogates workers' rights to a permanent contract if the employer exceeds the limit of temporary contracts - as a fraction of permanent ones, previously set at $20 \%$ - allowed to each firm. Therefore, temporary contracts have become cheaper for firms. This norm follows the socalled Decreto Poletti, introduced in May 2014, which removed the substantial economic requirements which needed to be fulfilled before the use of temporary contracts was allowed.

20 The reform also modified unemployment benefits, which we do not discuss here.
- Vouchers - The vouchers are hourly tickets used to compensate workers for accessory jobs for which the net hourly salary amounts to $€ 7.50$. They represent the Italian version of the German "mini-jobs". The Jobs Act increases the maximum amount of revenues that can be received in vouchers, from $€ 5,000$ to $€ 7,000$ per year. This regime strikes with the original aim of this job relationship because of the risk of being used for dependent work and not accessory one. In particular, workers under this kind of job relationship do not have any social security rights, while they have only a minimal social security contribution, threatening the sustainability of the social security system itself.

- Hiring incentives - Under the 2015 Budgetary Law, the government introduced a substantial monetary incentive for firms hiring workers on open-ended contracts, in order to stimulate the diffusion of the new type of contract - contratto a tutele crescenti. Each firm hiring a worker under a permanent contract in 2015 (including all conversions from a temporary to a permanent job) is exempted from paying contributions to social security up to $€ 8,060$ per year for three years.

The relevant novelty is that monetary incentives are no longer targeted towards specific groups (e.g. the longterm unemployed, youth, disabled people, women) or industries. Therefore, the new strategy does not seem to be based on a growth-oriented policy that is aimed at stimulating more efficient sectors or high-skill employment. Furthermore, the expected effect of these generous incentives - namely, an increase in the share of openended contracts - risks being counterbalanced, at least partially, by the opposite incentive for temporary contracts that is contained in the Jobs Act. The next section offers an empirical evaluation of the Jobs Act, focusing on employment dynamics and discussing potential structural implications.

\section{The consequences of the Jobs Act}

We now provide an initial descriptive assessment of employment trends - analysed in both quantitative and qualitative terms - since the Jobs Act. The ability of the reform to generate new jobs can be investigated using both statistical and administrative data. The analysis is carried out using data from the Italian National Statistical Institute (Istat), the Eurostat Labour Force Survey (LFS), and the Ministry of Labour and Social Security Institute (INPS) database. ${ }^{21}$

21 A detailed description of the databases can be found in M. Fana et al., op. cit. 
Table 1

\section{Contract distribution by type and working time}

\begin{tabular}{lccc} 
& \% of permanent & \% of temporary & $\%$ of total \\
\hline Full-time & 59 & 64 & 62 \\
\hline Part-time & 41 & 36 & 38 \\
\hline
\end{tabular}

Source: Authors' elaboration on INPS data.

Administrative data show that between January and October 2015, only ten per cent of newly signed contracts were new and permanent, with the majority of contracts either temporary or conversions of temporary contracts into permanent ones. ${ }^{22}$ While such contract transformations imply an increase in the share of overall permanent contracts, they do not represent new employment. Furthermore, comparing the dynamics of contract activations and dismissals across the last two years, one can note a net increase in permanent contracts, due mainly to the increase in activations, while the rate of contract dismissals is quite stable over the timespan considered. Moreover, the distribution of contracts by type of contract and working time (Table 1) shows that part-time jobs are more likely to offer new permanent contracts than fulltime jobs are..$^{23}$ More importantly, during the third quarter of 2015, involuntary part-time employment accounts for $64 \%$ of total part-time employment (and $11.9 \%$ of total employment), according to the Istat quarterly report.

Finally, according to INPS data, workers hired under the new contratto a tutele crescenti earn $1.5 \%$ less monthly than the cohort hired one year before under the old openended contract. ${ }^{24}$

In absolute terms, during the first ten months of 2015, the number of permanent employees increased by two thousands units. This is a very weak result, especially in light of the amount of incentives provided.

The combination of administrative and LFS data reveals that the monetary incentives did not lead to increased employment during the period under analysis. Thus, until now, this policy intervention has resulted in a pure distributive process from public finance to firms. Moreover, the moderate decrease in the unemployment rate observed

22 Note that each worker can hold more than one fixed-term contract.

23 The incidence of new part-time permanent contracts is higher than the incidence of total part-time employment, as shown in Table 1. This difference could be explained by the fact that we only take activation into account, and therefore the figures do not take dismissals into account.

24 See monthly report, "Osservatorio sul precariato", January-October 2015.
Figure 4

Share of workers by contract type, Italy, 2010-2015

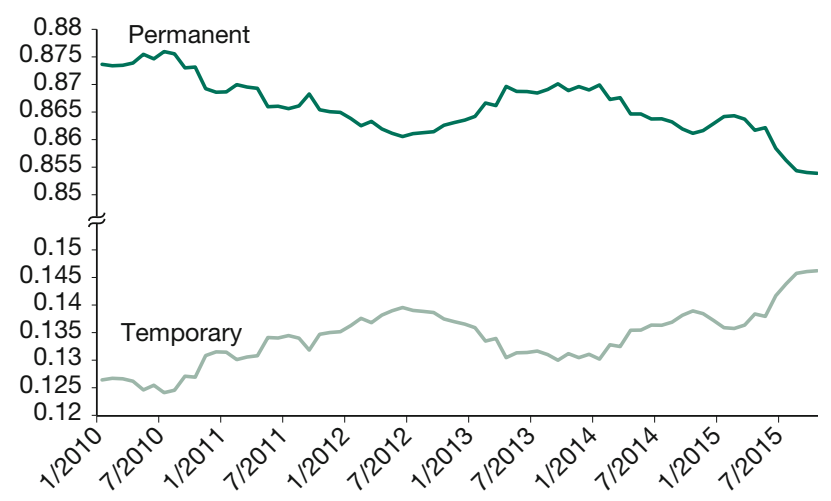

Source: Authors' elaboration on INPS data.

in 2015 seems to be due to the increase in the number of inactive individuals and not to the Jobs Act. Furthermore, the weak increase in permanent employment is also unevenly distributed across age cohorts: the decrease in the number of employees in the cohort 15-34 years old is offset by an equal increase in the cohort older than 55 years old. It seems that the Jobs Act is reducing the unemployment rate of older workers who cannot retire due to the recently delayed retirement age. ${ }^{25}$

The youth employment rate remains at its lowest level in recent history. In fact, during the examined period, the European Youth Guarantee programme was in place in Italy, with the goal of increasing the youth activity rate. According to data from the Italian Ministry of Labour, more than half a million young people not in education, employ-

25 The Legge Fornero implemented in 2011 modified the Italian pension system significantly, postponing the retirement age for both men and women.

Table 2

Vouchers sold per year, Italy 2008-2015

\begin{tabular}{lc} 
Year & Vouchers sold \\
\hline 2008 & 535985 \\
\hline 2009 & 2747768 \\
\hline 2010 & 9699503 \\
\hline 2011 & 15347163 \\
\hline 2012 & 23813978 \\
\hline 2013 & 40787817 \\
\hline Jan.-Oct. 2015 & 69186250 \\
\hline
\end{tabular}

Source: Authors' elaboration on INPS data. 


\section{Figure 5}

New employment by contract type, Italy, 2014-2015

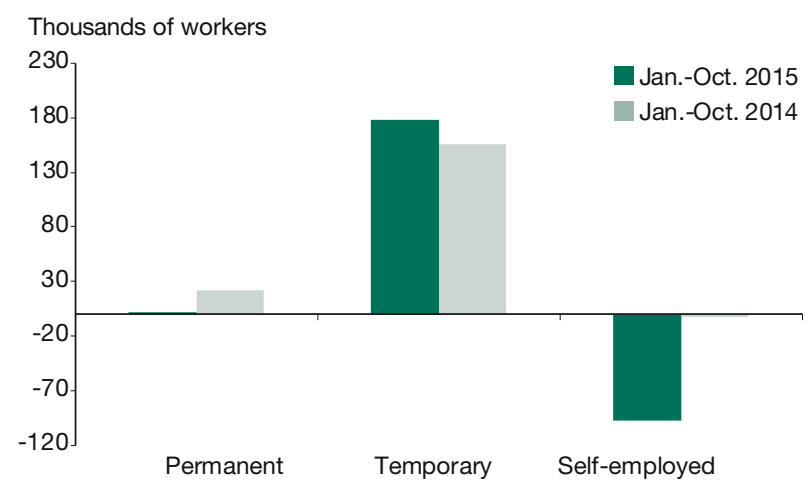

Source: Authors' elaboration on INPS data.

ment or training (NEETs) registered with the employment agencies to exit the NEET condition, thereby pushing down the unemployment rate due to an increase in the active population. ${ }^{26}$ Another feature of the Jobs Act is the further liberalisation of irregular job types. Among them, a leading role is played by vouchers, whose rising trend has continued unabated, as Table 2 shows. While this trend does not represent a novelty, having already begun with the first round of labour market liberalisation, this expansion is not slowing down under the Jobs Act. During the first ten months, more than 91 million job tickets had already been sold, at an annual growth rate equal to $70 \% .^{27}$

In structural terms, employment in the manufacturing sector has recovered weakly, while the services sector has continued to grow since the second half of 2014. This increasing trend is characterised, once again, by lowskill occupations, as already shown in Figure 3 . This evidence paints a worrisome picture, suggesting a structural change featuring a significant reduction in the manufacturing base - which is largely considered crucial to sustaining innovation and knowledge diffusion - in favour of an increase of low-tech services. In support of this thesis, it is worth emphasising that, even under the favourable fiscal treatment, firms do not appear to show any interest in increasing their competitiveness through any means other than a reduction in labour costs. The acceleration

26 See Ministero del Lavoro e delle Politiche Sociali: Monitoring the Youth Guarantee, http://www.garanziagiovani.gov.it.

27 The time series of vouchers sold by age groups, available through 2014 , shows that the share of young workers has drastically increased over time, while the opposite is true for those older than 55 years. Not only is the bargaining power of workers at a minimum under this type of job relationship, but more importantly, this evidence highlights the risks for productivity growth. of this process thus risks further undermining productivity and innovation in the medium to long run. ${ }^{28}$

\section{Conclusions}

The analysis developed in this article aims at evaluating the impact of the Jobs Act on the Italian labour market. The empirical investigation shows that the Jobs Act is failing to meet its main goals of boosting employment and reducing the share of temporary and atypical contracts. In fact, the only increase in employment that can be detected is a rise in temporary contracts (see Figure 5). This evidence signals that the increase in permanent contracts is mostly due to the transformation of temporary contracts to permanent ones and not to the creation of new jobs. However, excluding transformations, new permanent contracts (net of dismissals) were only $20 \%$ of the total contracts activated during the first nine months of 2015. Moreover, in terms of working hours, part-time contracts - primarily involuntary are more pronounced within new permanent positions than temporary ones.

Labour Force Survey data confirm that the increase in employment during the reform process has been weak and is mainly due to temporary jobs. In particular, the increase in permanent jobs is characterised by a labour force marked by low productivity, one in which during the first nine months only older workers have benefitted from the new type of contract for standard work. Yet encouraging changes in younger cohorts' employment and inactivity rates appear to be mainly associated with the European Youth Guarantee and the explosion of vouchers. The Jobs Act, in turn, has proved ineffective in reversing the historically high youth unemployment rate plaguing the Italian economy, which is confirmed by LFS data indicating outflows from unemployment into inactivity. As an additional remark, this initial phase of the Jobs Act seems to have increased the employment shift towards low-skilled and low-technology sectors. This element is especially worrisome if linked to the structural effects of the crisis - in particular, the significant reduction in productive capacity observed between 2008 and 2013.

In conclusion, the combination of supply-side policies analysed here - the Jobs Act and the provision of indiscriminate monetary incentives for firms hiring on open-ended contracts - has been shown to be ineffective in terms of the quantity, quality and duration of the jobs generated. Furthermore, such policies risk contributing to the further worsening of the Italian industrial structure, a process that has been accelerating since the 2008 crisis.

28 See M. Mazzucato et al., op. cit.; D. Rodrik: Premature Deindustrialization, National Bureau of Economic Research, Working Paper No. 20935, 2015. 